\title{
Interphotoreceptor Retinoid-Binding Protein as the Physiologically Relevant Carrier of 11-cis-Retinol in the Cone Visual Cycle
}

\author{
Ryan Parker, ${ }^{1}$ Jin-Shan Wang, ${ }^{3}$ Vladimir J. Kefalov, ${ }^{3}$ and Rosalie K. Crouch ${ }^{2}$ \\ Departments of ${ }^{1}$ Neurosciences and ${ }^{2}$ Ophthalmology, Medical University of South Carolina, Charleston, South Carolina 29403, and ${ }^{3}$ Department of \\ Ophthalmology and Visual Sciences, Washington University School of Medicine, St. Louis, Missouri 63110
}

Cones function in constant light and are responsible for mediating daytime human vision. Like rods, cones use the photosensitive molecule 11-cis-retinal to detect light, and in constant illumination, a continuous supply of 11-cis-retinal is needed. A retina visual cycle is thought to provide a privileged supply of 11-cis-retinal to cones by using 11-cis-retinol generated in Müller cells. In the cycle, 11-cisretinol is transported from Müller cells to cone inner segments, where it is oxidized to 11-cis-retinal. This oxidation step is only performed in cones, thus rendering the cycle cone-specific. Interphotoreceptor retinoid-binding protein (IRBP) is a retinoid-binding protein in the subretinal space that binds 11-cis-retinol endogenously. Cones in $I r b p^{-1-}$ mice are retinoid-deficient under photopic conditions, and it is possible that 11-cis-retinol supplies are disrupted in the absence of IRBP. We tested the hypothesis that IRBP facilitates the delivery of 11-cis-retinol to cones by preserving the isomeric state of 11-cis-retinol in light. With electrophysiology, we show that the cone-like photoreceptors of $\mathrm{Nrl}^{-1-}$ mice use the cone visual cycle similarly to wild-type cones. Then, using oxidation assays in isolated $\mathrm{Nrl}^{-1-} \mathrm{Rpe65^{-1- }}$ retinas, we show that IRBP delivers 11-cis-retinol for oxidation in cones and improves the efficiency of the oxidation reaction. Finally, we show that IRBP protects the isomeric state of 11-cis-retinol in the presence of light. Together, these findings suggest that IRBP plays an important role in the delivery of 11-cis-retinol to cones and can facilitate cone function in the presence of light.

\section{Introduction}

Photoreceptors depend on 11-cis-retinal to detect light. Within photoreceptor outer segments, 11-cis-retinal is bound to opsins to form visual pigments (Wald, 1935). When light strikes a visual pigment molecule, 11-cis-retinal is isomerized to all-transretinal, the opsin is activated, and phototransduction begins. Each photon is detected at the expense of a molecule of 11-cisretinal, and new 11-cis-retinal must be regenerated from the alltrans-retinal photoproduct for continued photoreceptor function. The classical visual cycle regenerates 11-cis-retinal from all-trans-retinal through reactions occurring in the photoreceptors and retinal pigment epithelium (RPE), but a second, conespecific visual cycle exists in the retina (Wang and Kefalov, 2009; Wang et al., 2009). Like the classical visual cycle, the cone visual cycle begins with the reduction of all-trans-retinal, but after leaving the outer segment, all-trans-retinol is transported to Müller

\footnotetext{
Received July 16, 2010; revised Jan. 18, 2011; accepted Jan. 27, 2011.

This study was supported by National Institutes of Health Grants EY04939 (R.K.C.), EY019312 (V.J.K.), EY14793 [Medical University of South Carolina (MUSC) Vision Core], and EY002687 (Department of Ophthalmology and Visual Sciences at Washington University); Foundation Fighting Blindness, Inc. (Owings Mills, MD) (to R.K.C.); and an unrestricted award to the Department of Ophthalmology at MUSC from Research to Prevent Blindness (RPB) (New York, NY). R.K.C. is an RPB Senior Scientific Investigator. R.P. is the recipient of an RPB Medical Student Eye Research Fellowship and V.J.K. is the recipient of an RPB Career Development Award. We thank Patrice Goletz for technical assistance and Dr. Luanna Bartholomew for editorial assistance.

Correspondence should be addressed to Ryan Parker, Storm Eye Institute, Medical University of South Carolina, 167 Ashley Avenue, Charleston, SC 29403. E-mail: parkerry@musc.edu.

DOI:10.1523/JNEUROSCI.3722-10.2011

Copyright $\odot 2011$ the authors $\quad 0270-6474 / 11 / 314714-06 \$ 15.00 / 0$
}

cells and converted to 11-cis-retinol (Mata et al., 2002, 2005). 11-cis-Retinol from Müller cells is transported to cones and oxidized to 11-cis-retinal (Jones et al., 1989; Wang et al., 2009). This final step is critical to the cycle's cone-specific nature, as only cones can oxidize 11-cis-retinol to 11-cis-retinal (Jones et al., 1989; Ala-Laurila et al., 2009).

The interphotoreceptor retinoid-binding protein (IRBP) is the most abundant soluble protein in the subretinal space (Gonzalez-Fernandez, 2003), and in vitro data suggest that IRBP facilitates the classical visual cycle by directing the flow of alltrans-retinol to the RPE (Okajima et al., 1994; Wu et al., 2007; Ala-Laurila et al., 2009), facilitating the return of 11-cis-retinal to photoreceptors (Jones et al., 1989; Edwards and Adler, 2000), and preserving the isomeric state of retinoids traversing the subretinal space (Crouch et al., 1992). While multiple studies using dark adaptation have shown that the classical visual cycle functions normally in $\mathrm{Irbp}^{-1-}$ mice (Palczewski et al., 1999; Ripps et al., 2000), cones in $I r b p^{-1-}$ mice are retinoid-deficient under photopic conditions (Parker et al., 2009) and undergo degeneration in some Irbp ${ }^{-1-}$ models (Jin et al., 2009). IRBP binds 11-cisretinol endogenously (Saari et al., 1985), and under photopic conditions IRBP is present at the outer limiting membrane where Müller cell processes and cone inner segments meet (Uehara et al., 1990). Thus, it is possible that IRBP facilitates cone function by transferring 11-cis-retinol from Müller cells to cones under photopic conditions.

The goal of the present study is to determine whether IRBP facilitates the delivery of 11-cis-retinol in the cone visual cycle. To 
A
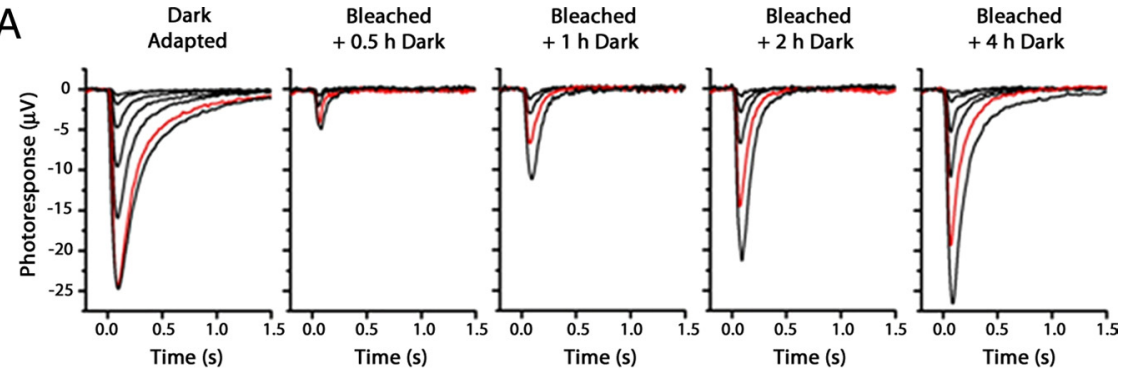

B

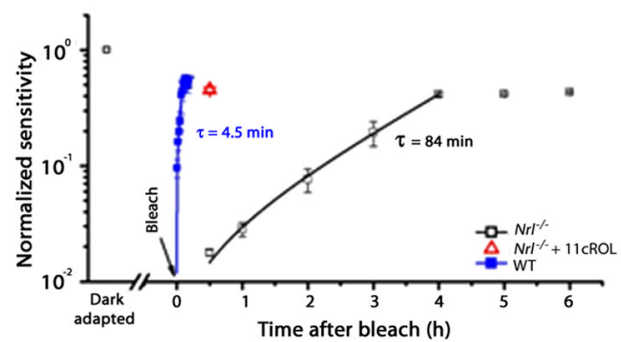

Bleached +11 cROL +0.5 h Dark

Figure 1. The retinas of mice lacking NRL have a functional cone visual cycle. $\boldsymbol{A}$, Cone trans-retinal ERG responses from darkadapted $\mathrm{Nrl}^{-1-}$ retina (left) and bleached retinas followed by different recovery times in darkness. The red traces represent the light responses elicited by 276,511 photons $\cdot \mu \mathrm{m}^{-2}$ at $500 \mathrm{~nm}$. $\boldsymbol{B}$, Kinetics of cone sensitivity recovery. Retinas were exposed to brief bleaching light at time 0 . It took $4 \mathrm{~h}$ for $\mathrm{Nrl}^{-1-}$ cones to recover their sensitivity to the plateau at $\sim 50 \%$ of its dark-adapted value (black trace, open squares), while WT cones recovered their sensitivity after an identical bleach to the same level within 10 $\min$ (blue trace, filled squares). Data were fitted by a single exponential function with $\tau=84{\text { min for } \mathrm{Nr}^{-1-}}^{-}$cones and $\tau=4.5$ min for WT cones. To determine the effects of 11-cis-retinol on the recovery of cone sensitivity, retinas were treated with $100 \mu \mathrm{m}$ 11 -cis-retinol in $0.1 \%$ ethanol and incubated at room temperature for $30 \mathrm{~min}$. Exogenous 11 -cis-retinol promoted rapid cone dark adaptation (red, open triangle). Sensitivity measurements were normalized to the corresponding dark-adapted value. Error bars indicate SEM; $n=3$. C, Post-bleach recovery of $\mathrm{Nrl}^{-1-}$ cone sensitivity was accelerated by exogenous 11-cis-retinol. Cone sensitivity reached the maximum level within $30 \mathrm{~min}$. The red traces represent the photo responses elicited by 276,511 photons $\cdot \mu \mathrm{m}^{-2}$ at $500 \mathrm{~nm}$.

address this question, we first show that the cone-like photoreceptors of $\mathrm{Nrl}^{-1-}$ mice use the cone visual cycle for visual pigment regeneration. Then, using oxidation assays in isolated retinas from $\mathrm{Nrl}^{-1-} \mathrm{Rpe}^{-1-}$ mice, we show that 11-cis-retinal is produced from 11-cis-retinol, that IRBP improves the efficiency of 11-cis-retinal production, and that IRBP helps preserve the isomeric state of 11-cis-retinol in light.

\section{Materials and Methods}

Animals. Experimental procedures and animal care protocols adhered to the Association for Research in Vision and Ophthalmology (ARVO) Statement for the Use of Animals in Ophthalmic and Vision Research and were approved by the Institutional Animal Care and Use Committee of the Medical University of South Carolina and of Washington University in Saint Louis. Mice lacking either the Nrl transcription factor $\left(\mathrm{Nrl}^{-/-}\right)$(Mears et al., 2001) or the rod transducin subunit $\alpha$ $\left(T r \alpha^{-I-}\right)$ (Calvert et al., 2000) were used to analyze the cone visual cycle function in isolated retina electroretinograms (ERGs). Oxidation assays used $\mathrm{Nrl}^{-1-} \mathrm{Rpe}^{-1-}$ mice between postnatal day 17 (P17) and P22 unless otherwise noted. Both male and female littermates were used.

Isolated retina ERGs. In vitro trans-retinal ERGs were recorded as described previously (Wang and Kefalov, 2009; Wang et al., 2009). Briefly, eyes of dark-adapted mice were enucleated under dim red light. Under infrared light, the eyeballs were hemisected and the retinas were placed in oxygenated L-15 medium. The retina was exposed to $40 \mathrm{~s}$ bright light (95\% bleach) and put in darkness with or without 11-cis-retinol. At different time points after bleaching a piece of retina was transferred on nitrocellulose filter paper to a recording chamber and photoreceptor light responses were recorded with electrodes placed under and above the retina. The retina was perfused with Ringer solution at $37^{\circ} \mathrm{C}$ containing a mixture of synaptic inhibitors: $2 \mathrm{~mm} \mathrm{~L}$-aspartate, $\mathrm{pH} 7.4$, and $5 \mu \mathrm{M} \mathrm{L}-(+)-$ 2-amino-4-phosphonobutyric acid to block on-bipolar cell signals (Thoreson and Ulphani, 1995; Winkler et al., 1999), 5 м M 2,3-dioxo-6nitro-1,2,3,4-tetrahydrobenzo[f] quinoxaline-7-sulfonamide to block AMPA/kainate signals ( $\mathrm{Yu}$ and Miller, 1995), and $50 \mu \mathrm{M}$ D-2-amino-5phosphonovalerate to block NMDA signals (Coleman and Miller, 1988). Barium chloride $(10 \mathrm{~mm})$ was added to the solution in the reference electrode proximate to the ganglion cell layer to suppress glial components of the photoresponse (Green and Kapousta-Bruneau, 1999). Test flashes ( $20 \mathrm{~ms}, 500 \mathrm{~nm})$ were delivered from an optical bench using calibrated neutral density filters. Photosensitivity was calculated from the linear region of the intensityresponse curve as the ratio of response amplitude and flash intensity.

Isolated retina oxidation assays. IRBP for all studies was provided by Barbara Wiggert and Todd Duncan (National Eye Institute, Bethesda, MD). Retinas ( $n=6$ per data point) were dissected from the RPE in Ringer's solution modified for mammalian tissue (in mM: $130 \mathrm{NaCl}, 5 \mathrm{KCl}, 0.5 \mathrm{MgCl}_{2}, 2 \mathrm{CaCl}_{2}, 25$ hemisodium-HEPES, 5 glucose, $\mathrm{pH}=7.40$ ). Retinas were suspended in $450 \mu$ l of Ringer's and $50 \mu \mathrm{l}$ of carrier (IRBP or BSA, as noted) plus retinoids were added to achieve the final concentrations noted for each experiment. Samples were incubated at $37^{\circ} \mathrm{C}$ in the dark for the periods described for each experiment. Following incubation, retinas were washed five times with $1 \mathrm{ml}$ of ice-cold PBS and retinoids were extracted.

Retinoid extraction and HPLC analysis. Under dim red light, retinoids were extracted with modifications of a previously described method (Fan et al., 2003). Retinas $(n=6)$ were homogenized in PBS buffer $(200 \mu \mathrm{l})$ in a micro-tissue grinder. Methanol (300 $\mu \mathrm{l})$ and hydroxylamine (60 $\mu \mathrm{l}, 1 \mathrm{~m}$ in PBS, pH 7.4) were added, and samples were vortexed (30 s). After $5 \mathrm{~min}$, samples were mixed with methylene chloride $(300 \mu \mathrm{l})$ and centrifuged $(16,000 \times g, 1 \mathrm{~min})$. The lower phase was dried under argon. Samples were dissolved in the HPLC mobile phase ( $91.8 \%$ hexane $/ 6.6 \%$ ethyl acetate $/ 0.8 \%$ dioxane/ $0.8 \%$ octanol), and retinoids were separated by using a Lichrosphere SI-60, $5 \mu \mathrm{m}$ column (Alltech Associates). Retinals were identified by comparison with pure isomeric standards and quantified by adding syn- and anti-peaks measured at $360 \mathrm{~nm}$.

11-cis-Retinol protection assay. Fixed amounts of 11-cis-retinol (10 $\mu \mathrm{M}$ ) in $300 \mu \mathrm{l}$ of medium were used under all experimental conditions. For non-IRBP samples, $1 \mu \mathrm{l}$ of $3 \mathrm{~mm}$ 11-cis-retinol (in ethanol) was added to $30 \mu \mathrm{l}$ of medium, mixed, and transferred into $270 \mu \mathrm{l}$ of medium (300 $\mu \mathrm{l}$ of $10 \mu \mathrm{M} 11$-cis-retinol). For IRBP-containing samples, $1 \mu \mathrm{l}$ of 3 mM 11-cis-retinol (in ethanol) was added to $30 \mu \mathrm{l}$ of $150 \mu \mathrm{M}$ IRBP, mixed, and transferred into $270 \mu \mathrm{l}$ of medium (300 $\mu \mathrm{l}$ of $10 \mu \mathrm{M}$ 11-cis-retinol and $15 \mu \mathrm{M}$ IRBP). Dark samples were incubated in an ERG ganzfeld in the absence of light for $30 \mathrm{~s}$. Light-treated samples were exposed to UV light $\left(10 \mathrm{~cd} / \mathrm{m}^{2} ; 360 \mathrm{~nm}\right)$ for $30 \mathrm{~s}$ in the ganzfeld. After the treatment period, retinoids were extracted with methanol and methylene chloride as described above and analyzed using the same HPLC protocol. The area under the 11-cis-retinol curve at $320 \mathrm{~nm}$ for each sample was calculated and compared with the 11-cis-retinol extracted from $1 \mu \mathrm{l}$ of stock $3 \mathrm{~mm}$ 11-cis-retinol. Results were expressed as the percentage of 11-cis-retinol extracted (sample/stock).

\section{Results}

The cone visual cycle is functional in the $\mathrm{Nrl}^{-/-}$mouse retina Mice lacking the $\mathrm{Nrl}$ transcription factor $\left(\mathrm{Nrl}^{-/-}\right)$contain a homogenous population of photoreceptors with many cone-like 
characteristics (Mears et al., 2001; Daniele et al., 2005; Nikonov et al., 2005), and the retinas of these animals represent a useful tool for biochemical studies of cone-specific reactions, including the cone visual cycle. Physiological studies from wild-type (WT) and $\operatorname{Tr} \alpha^{-1-}$ mice show the robust function of a cone visual cycle in the mouse retina that promotes pigment regeneration and dark adaptation selectively in cones (Wang and Kefalov, 2009; Wang et al., 2009). However, previous studies form $\mathrm{Nrl}^{-1-}$ mice have suggested that their retinas have no functional visual cycle and that their cones cannot undergo pigment regeneration without the help of the pigment epithelium (Wenzel et al., 2007; Feathers et al., 2008). Thus, we first performed electrophysiological experiments to determine whether the $\mathrm{Nrl}^{-/-}$retina is able to promote cone pigment regeneration independent of the RPE. We used the $a$-wave response from in vitro ERG recordings to measure the sensitivity of WT and $\mathrm{Nrl}^{-1-}$ cones in darkness and then at different time points following exposure to bright light that bleached most of their pigment. For convenience, WT cone function was assessed using $\operatorname{rod} \operatorname{Tr} \alpha^{-1-}$. The deletion of $\operatorname{Tr} \alpha$ renders rods unable to respond to light but does not affect the morphology or functional properties of cones (Nikonov et al., 2006).

In contrast to the rapid recovery of WT cones in the isolated retina (Wang and Kefalov, 2009), $\mathrm{Nrl}^{-1-}$ cones did not show detectable recovery within the first $0.5 \mathrm{~h}$ following the bleach. However, they did recover gradually over the time course of $4 \mathrm{~h}$ (Fig. 1A). The WT cone recovery could be described by a single exponential function with a time-constant of $4.5 \mathrm{~min}$. The time constant of $\mathrm{Nrl}^{-1-}$ cone recovery was $84 \mathrm{~min}, \sim 20$-fold slower than that of WT cones. Notably, however, the final level of recovery of sensitivity in $\mathrm{Nrl}^{-1-}$ cones $(41 \pm 1.2 \%, n=3)$ was comparable to that of cones from $\operatorname{Tr} \alpha^{-1-}$ retinas $(48 \pm 8.1 \%, n=6)$ (Fig. $1 B$ ). Thus, the $\mathrm{Nrl}$-deficient retina could promote the pigment regeneration and dark adaptation of cones similar to WT retina. To understand the slower recovery of $\mathrm{Nrl}^{-1-}$ cones, we applied exogenous 11-cis-retinol immediately following the bleach (Fig. $1 B, C$ ) to bypass the need for recycling of chromophore by the retina visual cycle. This greatly accelerated the recovery of $\mathrm{Nrl}^{-1-}$ cones so that their sensitivity returned to $45 \pm$ $2.1 \%(n=3)$ of its dark-adapted level within $30 \mathrm{~min}$ following the bleach. Thus, chromophore recycling through the retina visual cycle was the rate-limiting step for cone dark-adaptation in $\mathrm{Nrl}^{-1-}$ retina. The functional cone visual cycle in the $\mathrm{Nrl}^{-1-}$ retina allowed us to perform cone-specific biochemical studies with these animals to investigate the role of IRBP in the retina visual cycle.

\section{1-cis-Retinol is oxidized in $\mathrm{Nrl}^{-/-} \mathrm{Rpe65^{-/- }}$ retinas}

Cones are uniquely able to oxidize 11-cis-retinol to 11-cis-retinal (Jones et al., 1989; Ala-Laurila et al., 2009). To demonstrate IRBP's efficacy as a vehicle for 11-cis-retinol delivery to cones, isolated retinas from $\mathrm{Nrl}^{-1-} \mathrm{Rpe65^{-1- }}$ mice were treated with IRBP $(24 \mu \mathrm{M})$ and 11-cis-retinol $(24 \mu \mathrm{M})$, and HPLC analysis of extracted retinoids was used to follow the formation of 11-cisretinal. $\mathrm{Nrl}^{-1-} \mathrm{Rpe} 65^{-1-}$ retinas were essentially devoid of endogenous 11-cis-retinal, but after treatment with IRBP and 11-cis-retinol, 11-cis-retinal was detectable (Fig. 2A). The retina contains multiple retinol dehydrogenases (RDHs) capable of oxidizing 11-cis-retinol to 11-cis-retinal. To determine whether oxidation takes place in the photoreceptors, which degenerate in aging $\mathrm{Nrl}^{-1-} \mathrm{Rpe65}^{-1-}$ mice (Kunchithapautham et al., 2009), retinas from $\mathrm{Nrl}^{-1-} \mathrm{Rpe65^{-1- }}$ mice at increasing ages were incubated with IRBP $(15 \mu \mathrm{M})$ and 11-cis-retinol $(10 \mu \mathrm{M})$ for $60 \mathrm{~min}$, and 11-cis-retinal production was analyzed. Figure $2 B$ shows that 11-cis-retinal production declined sharply when older
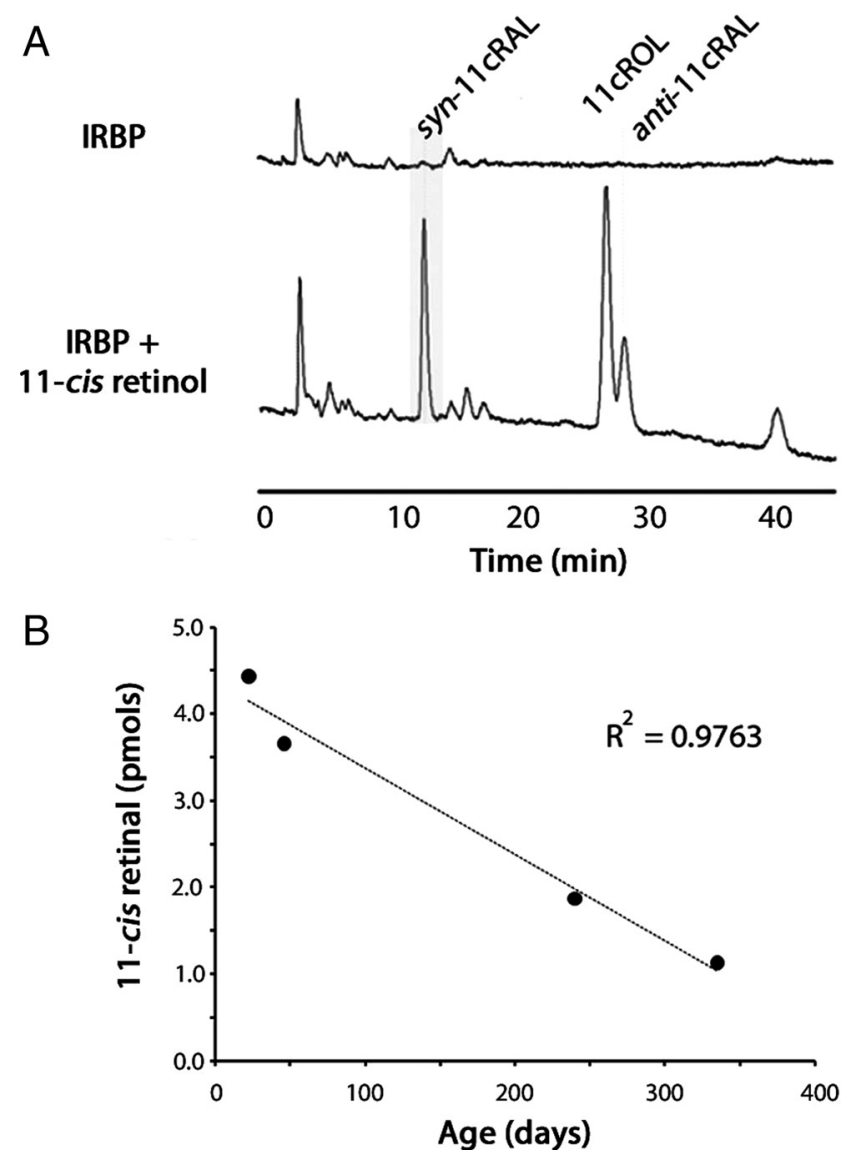

Figure 2. 11-cis-Retinol is oxidized in $\mathrm{Nrl}^{-/-}$Rpe65 $5^{-1-}$ retinas. $\mathrm{A}, \mathrm{HPLC}$ traces of retinoids extracted from six $\mathrm{Nrl}^{-1-} \mathrm{Rpe65}^{-1-}$ (P17) retinas. After incubating (60 min) with IRBP $(24 \mu \mathrm{m})$ alone, 11-cis-retinal (11-CRAL) was essentially absent. After treating with IRBP $(24 \mu \mathrm{m})$ and 11-cisretinol (11-CROL) (24 $\mu \mathrm{M}), 11$-cis-retinal was generated in the retinas. $B, 11$-cis-Retinal production in isolated retinas from $\mathrm{Nrl}^{-1-}$ Rpe65 ${ }^{-1-}$ mice of increasing age. The decline in 11-cis-retinal production corresponds to the loss of photoreceptors seen in $\mathrm{Nrl}^{-1-} \mathrm{Rpe}^{-1-}$ mice, suggesting that 11-cis-retinal production occurred in the photoreceptors. Data points represent mean values of 11-cisretinal per retina obtained from three samples with four retinas used per sample.

retinas were used, suggesting that oxidation occurred in the photoreceptors.

\section{1-cis-Retinol is the preferred substrate for oxidation in isolated retinas}

In rod-dominant retinas under photopic conditions, all-transretinol is the major retinoid present in the subretinal space and the major retinoid bound to IRBP (Saari et al., 1982). For a cone visual cycle to function effectively, 11-cis-retinol must be the preferred substrate for oxidation. To determine whether retinas are able to preferentially oxidize 11-cis-retinol over all-trans-retinol, IRBP $(24 \mu \mathrm{M})$ was used to deliver all-trans-retinol or 11-cis-retinol (10 $\mu \mathrm{M})$ to isolated retinas from $\mathrm{Nrl}^{-1-} \mathrm{Rpe} 65^{-1-}$ mice, and the generation of all-trans-retinal or 11-cis-retinal, respectively, was analyzed. Compared with control samples (IRBP treated), all-trans-retinal levels were unchanged when all-trans-retinol is delivered with IRBP (IRBP, $1.98 \pm 0.45$; IRBP:all-trans-retinol, $2.28 \pm 0.27$ pmol alltrans-retinal/retina; $n=4 ; p=0.52$ ). However, the use of IRBP to deliver 11-cis-retinol resulted in a significant increase in 11-cisretinal levels (IRBP, $0.39 \pm 0.08$; IRBP:11-cis-retinol, $2.36 \pm 0.39$ pmol 11-cis-retinal/retina; $n=4 ; p=0.001$ ) (Fig. 3). Thus, 11-cis-retinol was the preferred substrate for oxidation in isolated $\mathrm{Nrl} \mathrm{I}^{-1-} \mathrm{Rpe65^{-1- }}$ retinas. 


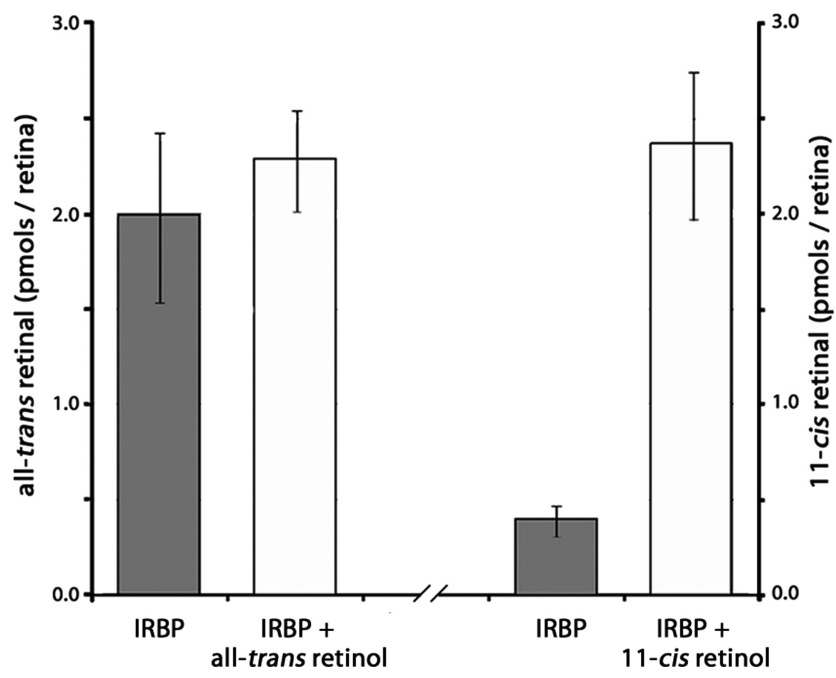

Figure 3. 11-cis-Retinol is the preferred substrate for oxidation in the retina. To determine whether 11-cis-retinol is the preferred substrate for oxidation in the retina, isolated retinas from $\mathrm{Nrl}^{-1-}$ Rpe65 ${ }^{-1-}$ mice were treated with IRBP $(24 \mu \mathrm{M})$ and either all-trans-retinol $(n=4)$ or 11-cis-retinol $(n=4)$. After 60 min, retinoids were extracted and levels of all-trans-retinal or 11-cis-retinal were measured by HPLC. The use of IRBP to deliver all-trans-retinol did not result in an increase in all-trans-retinal ( $p=0.52$ ). However, the use of IRBP to deliver 11-cis-retinol resulted in a significant increase in 11-cis-retinal ( $p=0.001)$.

\section{IRBP improves the efficiency of 11-cis-retinol oxidation}

11-cis-Retinol is inherently unstable, and its preservation is limited in the aqueous environment of the subretinal space at $37^{\circ} \mathrm{C}$. Preserving the isomeric state of 11-cis-retinol is critical for an effective cone visual cycle. To determine whether IRBP is effective at preserving the isomeric state of 11-cis-retinol, isolated retinas were treated with 11-cis-retinol ( $5 \mu \mathrm{M})$ using either IRBP or BSA $(15 \mu \mathrm{M})$ as a carrier. After $60 \mathrm{~min}$ at $37^{\circ} \mathrm{C}$, retinoids were extracted and analyzed by HPLC, and 11-cis-retinal production was analyzed as a percentage of total retinoids. BSA-treated retinas contained $35 \pm 3.1 \%$ 11-cis-retinal, while IRBP-treated retinas contained $62 \pm 2.1 \%(n=4 ; p<0.001)$. In addition to decreased 11-cis-retinal levels in the BSA-treated retinas, all-trans-retinol levels were elevated (BSA, $44 \pm 0.73 \%$; IRBP, $25 \pm 1.3 \%$; $n=4$; $p=0.01$ ) (Fig. 4), suggesting that 11-cis-retinol was less stable in the presence of BSA. Thus, IRBP effectively preserved the isomeric state of 11-cis-retinol and increased the efficiency of 11-cisretinal production.

\section{IRBP protects 11-cis-retinol from photoisomerization}

Of critical importance to a functioning cone visual cycle is the ability to generate new visual pigment under photopic conditions. IRBP protects the isomeric state of 11-cis-retinal (Crouch et al., 1992) and may also help protect 11-cis-retinol under photopic conditions. To test the ability of IRBP to protect 11-cisretinol, we exposed fixed concentrations of 11-cis-retinol (10 $\mu \mathrm{M}$ in medium) to light in the presence and absence of IRBP (Fig. 5). Under control conditions (no carrier, dark), $57 \pm 8.3 \%$ of the 11-cis-retinol added was recovered. When 11-cis-retinol under these conditions (no carrier) was incubated in light, only $7 \pm$ $1.2 \%$ of the 11-cis-retinol was recovered. Thus, the presence of light resulted in a significant loss of 11-cis-retinol in the absence of IRBP $(n=4 ; p=0.008)$. The effect of light on 11-cis-retinol was dramatically different in the presence of IRBP $(15 \mu \mathrm{M})$. Under dark conditions, $54 \pm 4.1 \%$ of the 11-cis-retinol was recovered. Similarly, $56 \pm 2.4 \%$ of 11 -cis-retinol was recovered when 11-cis-retinol was exposed to light in the presence of IRBP $(n=4$;

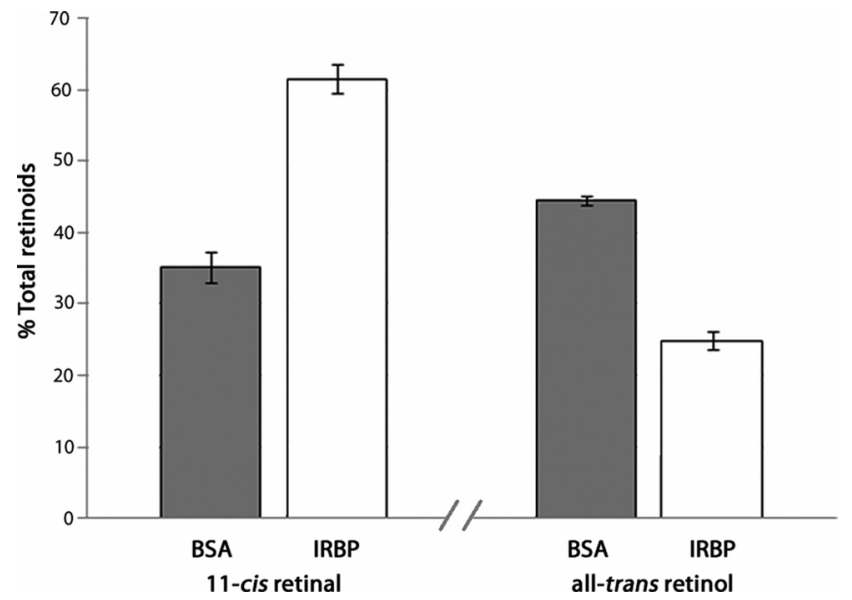

Figure 4. IRBP improves the efficiency of 11-cis-retinal production in $\mathrm{Nrl}^{-1-}$ Rpe65 $5^{-1-}$ retinas. Isolated retinas were treated with 11-cis-retinol $(5 \mu \mathrm{M})$ using either BSA or IRBP (15 $\mu \mathrm{M})$ as carriers. The use of IRBP resulted in higher percentages of 11-cis-retinal $(n=4 ; p=$ 0.001 ) and lower amounts of side-products, such as all-trans-retinol ( $n=4 ; p=0.01)$, after 60 min at $37^{\circ} \mathrm{C}$. Thus, IRBP helps preserve the isomeric state of 11-cis-retinol and improves the efficiency of 11-cis-retinal production.

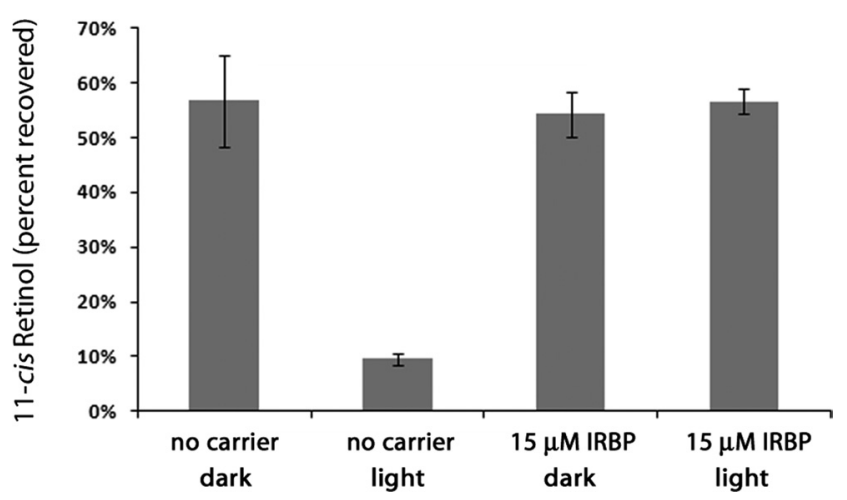

Figure 5. IRBP protects the isomeric state of 11-cis-retinol. 11-cis-Retinol $(10 \mu \mathrm{m})$ was exposed to light in the presence or absence of IRBP. In control conditions (no carrier), the addition of light caused a significant reduction in the levels of 11-cis-retinol extracted $(n=4$; $p=0.008)$. In the presence of IRBP $(15 \mu \mathrm{M})$, exposure to light had no effect on 11-cis-retinol levels $(n=4 ; p=0.59)$. Thus, IRBP protects 11 -cis-retinol from photodegradation. Data points represent means $\pm 1 S D$.

$p=0.59)$. Thus, IRBP has the ability to preserve the isomeric state of 11-cis-retinol in light, in addition to its ability to deliver 11-cisretinol to cones.

\section{Discussion}

Importance of the oxidation reaction to the cone visual cycle Cone dysfunction in $I r b p^{-1-}$ mice is evident through reduced photopic ERGs (Ripps et al., 2000; Parker et al., 2009), and the improvement of cone responses to WT levels after treatment with exogenous 9-cis-retinal suggests that the cones are chromophoredeficient under photopic conditions (Parker et al., 2009). A cone visual cycle is thought to provide cones with a unique source of chromophore to facilitate the high demand for 11-cis-retinal under photopic conditions. The aspect of the cone visual cycle responsible for its cone-specific nature is the supply of 11-cisretinol to cone inner segments, as only cones have the ability to oxidize 11-cis-retinol to 11-cis-retinal. The source of 11-cisretinol is proposed to be Müller cells, and multiple studies have shown that Müller cells have the ability to generate 11-cis-retinol from all-trans-retinol (Mata et al., 2002, 2005). IRBP is known to 
bind 11-cis-retinol endogenously, and under photopic conditions IRBP is localized to the outer limiting membrane where the microvilli of Müller cells are in close proximity to cone inner segments (Uehara et al., 1990). As such, IRBP is located in the appropriate area to facilitate the transport of 11-cis-retinol from Müller cells to cones.

\section{Oxidation of 11-cis-retinol in $\mathrm{Nrl}^{-/-}$photoreceptors}

Studying the cone visual cycle in $\mathrm{Nrl}^{-1-}$ mice is potentially advantageous, as the large number of cone-like photoreceptors increases the sensitivity of assays. However, a fundamental question that must be addressed before using the model is whether the cone-like photoreceptors in $\mathrm{Nrl}^{-1-}$ mice function as cones in the retina visual cycle. Here, we have shown that $\mathrm{Nrl}^{-1-}$ retinas, like WT retinas, can recover both response amplitude and sensitivity in cones following a bleach (Fig. 1). Furthermore, we have shown that isolated retinas from $\mathrm{Nrl}^{-1-} \mathrm{Rpe65^{-/- }}$ mice can oxidize 11cis-retinol into 11-cis-retinal (Fig. 2A). Reduced 11-cis-retinal production as photoreceptors degenerate with age suggests that this reaction occurs within the photoreceptors and not within other cells containing RDH enzymes (Farjo et al., 2009; Parker and Crouch, 2010b) (Fig. $2 \mathrm{~B}$ ). While cones in isolated $\mathrm{Nrl}^{-1-}$ retinas recover their sensitivity and response amplitude, the time course of this recovery is slower than that seen in WT retinas. This delay may be due to the fact that $\mathrm{Nrl}^{-1-}$ photoreceptors are more numerous than cones in WT mice, and more time is required to regenerate the full complement of pigment needed to restore their dark-adapted state. With exogenous 11-cis-retinol, however, the time course for recovery is rapid and comparable in kinetics to that in WT retinas. Thus, the generation of 11-cisretinol is likely the rate-limiting step of the cone visual cycle in $\mathrm{Nrl}^{-1-}$ retinas.

\section{Characterization of the oxidation reaction in cones}

The cone visual cycle depends on a relatively small amount of 11-cis-retinol reaching the cone inner segments in the presence of an overwhelming amount of all-trans-retinol (Saari et al., 1982). One characteristic of intact retinas that facilitates the cone visual cycle is the preference for 11-cis-retinol in oxidation reactions. IRBP binds both all-trans-retinol and 11-cis-retinol under photopic conditions (Adler and Spencer, 1991). If all-trans-retinol were readily delivered to cones, its oxidation to all-trans-retinal could interfere with oxidation of 11-cis-retinol. While IRBP readily binds all-trans-retinol, promotes its release from both rods and cones, and effectively delivers all-trans-retinol to the RPE, we have shown here that it is ineffective at delivering all-transretinol to photoreceptors for oxidation (Fig. 3). Electron microscopy studies of IRBP bound to either all-trans-retinol or 11-cis-retinol suggest that IRBP undergoes a structural change when bound by either ligand (Adler et al., 1987). Thus, the binding of different retinoids to IRBP results in conformation changes to the protein, and it is possible that these changes promote tissue-specific delivery of retinoids. Also, it is possible that an unidentified 11-cis-RDH is responsible for the oxidation of 11-cis-retinol in cones and all-trans-retinol is not a usable substrate for that RDH. Regardless of the mechanism, the selective delivery or oxidation of 11-cis-retinol would facilitate the cone visual cycle.

\section{Importance of IRBP to the oxidation reaction of the cone visual cycle}

11-cis-Retinol is highly unstable and undergoes rapid isomerization and degradation under physiological conditions. This is in- creased further in the presence of light. IRBP is known to preserve the isomeric state of 11-cis-retinal (Crouch et al., 1992), and here we have shown that it also helps preserve 11-cis-retinol under physiological conditions (Fig. 4). The result of this protection is the more efficient production of 11-cis-retinal and reduced levels all-trans-retinol. Furthermore, IRBP's ability to protect 11-cisretinol in the presence of light would allow 11-cis-retinal to be generated in light (Fig. 5). Because the cone visual cycle should be able to provide cones with 11-cis-retinal under photopic conditions, these findings, coupled with the reduced chromophore levels known to be present in Irbp ${ }^{-1-}$ mice under photopic conditions (Parker et al., 2009; Parker and Crouch, 2010a), suggest that IRBP plays an important role in normal cone function.

\section{Summary}

The cone-like photoreceptors of $\mathrm{Nrl}^{-1-}$ mice are similar to WT cones in their ability to oxidize 11-cis-retinol to 11-cis-retinal and use the retina visual cycle. IRBP is an effective vehicle for delivering 11-cis-retinol to cones and increases the efficiency of 11-cisretinal production under physiological conditions. The ability of IRBP to protect 11-cis-retinol from isomerization in light may allow cones to produce 11-cis-retinal under photopic conditions and enable continuous cone function in constant light.

\section{References}

Adler AJ, Spencer SA (1991) Effect of light on endogenous ligands carried by interphotoreceptor retinoid-binding protein. Exp Eye Res 53:337-346.

Adler AJ, Stafford WF 3rd, Slayter HS (1987) Size and shape of bovine interphotoreceptor retinoid-binding protein by electron microscopy and hydrodynamic analysis. J Biol Chem 262:13198-13203.

Ala-Laurila P, Cornwall MC, Crouch RK, Kono M (2009) The action of 11-cis-retinol on cone opsins and intact cone photoreceptors. J Biol Chem 284:16492-16500.

Calvert PD, Krasnoperova NV, Lyubarsky AL, Isayama T, Nicoló M, Kosaras B, Wong G, Gannon KS, Margolskee RF, Sidman RL, Pugh EN Jr, Makino CL, Lem J (2000) Phototransduction in transgenic mice after targeted deletion of the rod transducin alpha-subunit. Proc Natl Acad Sci U S A 97:13913-13918.

Coleman PA, Miller RF (1988) Do N-methyl-D-aspartate receptors mediate synaptic responses in the mudpuppy retina? J Neurosci 8:4728-4733.

Crouch RK, Hazard ES, Lind T, Wiggert B, Chader G, Corson DW (1992) Interphotoreceptor retinoid-binding protein and alpha-tocopherol preserve the isomeric and oxidation state of retinol. Photochem Photobiol 56:251-255.

Daniele LL, Lillo C, Lyubarsky AL, Nikonov SS, Philp N, Mears AJ, Swaroop A, Williams DS, Pugh EN Jr (2005) Cone-like morphological, molecular, and electrophysiological features of the photoreceptors of the $\mathrm{Nrl}$ knockout mouse. Invest Ophthalmol Vis Sci 46:2156-2167.

Edwards RB, Adler AJ (2000) IRBP enhances removal of 11-cisretinaldehyde from isolated RPE membranes. Exp Eye Res 70:235-245.

Fan J, Rohrer B, Moiseyev G, Ma JX, Crouch RK (2003) Isorhodopsin rather than rhodopsin mediates rod function in RPE65 knock-out mice. Proc Natl Acad Sci U S A 100:13662-13667.

Farjo KM, Moiseyev G, Takahashi Y, Crouch RK, Ma JX (2009) The 11-cisretinol dehydrogenase activity of RDH10 and its interaction with visual cycle proteins. Invest Ophthalmol Vis Sci 50:5089-5097.

Feathers KL, Lyubarsky AL, Khan NW, Teofilo K, Swaroop A, Williams DS, Pugh EN Jr, Thompson DA (2008) Nrl-knockout mice deficient in Rpe65 fail to synthesize 11-cis retinal and cone outer segments. Invest Ophthalmol Vis Sci 49:1126-1135.

Gonzalez-Fernandez F (2003) Interphotoreceptor retinoid-binding protein - an old gene for new eyes. Vision Res 43:3021-3036.

Green DG, Kapousta-Bruneau NV (1999) A dissection of the electroretinogram from the isolated rat retina with microelectrodes and drugs. Vis Neurosci 16:727-741.

Jin M, Li S, Nusinowitz S, Lloyd M, Hu J, Radu RA, Bok D, Travis GH (2009) The role of interphotoreceptor retinoid-binding protein on the translocation of visual retinoids and function of cone photoreceptors. J Neurosci 29:1486-1495. 
Jones GJ, Crouch RK, Wiggert B, Cornwall MC, Chader GJ (1989) Retinoid requirements for recovery of sensitivity after visual-pigment bleaching in isolated photoreceptors. Proc Natl Acad Sci U S A 86:9606-9610.

Kunchithapautham K, Coughlin B, Crouch RK, Rohrer B (2009) Cone outer segment morphology and cone function in the Rpe65-/ - Nrl-/mouse retina are amenable to retinoid replacement. Invest Ophthalmol Vis Sci 50:4858-4864.

Mata NL, Radu RA, Clemmons RC, Travis GH (2002) Isomerization and oxidation of vitamin A in cone-dominant retinas: a novel pathway for visual-pigment regeneration in daylight. Neuron 36:69-80.

Mata NL, Ruiz A, Radu RA, Bui TV, Travis GH (2005) Chicken retinas contain a retinoid isomerase activity that catalyzes the direct conversion of all-trans-retinol to 11-cis-retinol. Biochemistry 44:11715-11721.

Mears AJ, Kondo M, Swain PK, Takada Y, Bush RA, Saunders TL, Sieving PA, Swaroop A (2001) $\mathrm{Nrl}$ is required for rod photoreceptor development. Nat Genet 29:447-452.

Nikonov SS, Daniele LL, Zhu X, Craft CM, Swaroop A, Pugh EN Jr (2005) Photoreceptors of $\mathrm{Nrl}-/-$ mice coexpress functional S- and M-cone opsins having distinct inactivation mechanisms. J Gen Physiol 125:287-304.

Nikonov SS, Kholodenko R, Lem J, Pugh EN Jr (2006) Physiological features of the $\mathrm{S}$ - and $\mathrm{M}$-cone photoreceptors of wild-type mice from singlecell recordings. J Gen Physiol 127:359-374.

Okajima TI, Wiggert B, Chader GJ, Pepperberg DR (1994) Retinoid processing in retinal pigment epithelium of toad (Bufo marinus). J Biol Chem 269:21983-21989.

Palczewski K, Van Hooser JP, Garwin GG, Chen J, Liou GI, Saari JC (1999) Kinetics of visual pigment regeneration in excised mouse eyes and in mice with a targeted disruption of the gene encoding interphotoreceptor retinoid-binding protein or arrestin. Biochemistry 38:12012-12019.

Parker RO, Crouch RK (2010a) The interphotoreceptor retinoid binding (IRBP) is essential for normal retinoid processing in cone photoreceptors. Adv Exp Med Biol 664:141-149.

Parker RO, Crouch RK (2010b) Retinol dehydrogenases (RDHs) in the visual cycle. Exp Eye Res 91:788-792.

Parker RO, Fan J, Nickerson JM, Liou GI, Crouch RK (2009) Normal cone function requires the interphotoreceptor retinoid binding protein. J Neurosci 29:4616-4621.

Ripps H, Peachey NS, Xu X, Nozell SE, Smith SB, Liou GI (2000) The rhodopsin cycle is preserved in IRBP "knockout" mice despite abnormalities in retinal structure and function. Vis Neurosci 17:97-105.

Saari JC, Bredberg L, Garwin GG (1982) Identification of the endogenous retinoids associated with three cellular retinoid-binding proteins from bovine retina and retinal pigment epithelium. J Biol Chem 257:13329-13333.

Saari JC, Teller DC, Crabb JW, Bredberg L (1985) Properties of an interphotoreceptor retinoid-binding protein from bovine retina. J Biol Chem 260:195-201.

Thoreson WB, Ulphani JS (1995) Pharmacology of selective and nonselective metabotropic glutamate receptor agonists at L-AP4 receptors in retinal ON bipolar cells. Brain Res 676:93-102.

Uehara F, Matthes MT, Yasumura D, LaVail MM (1990) Light-evoked changes in the interphotoreceptor matrix. Science 248:1633-1636.

Wald G (1935) Carotenoids and the visual cycle. J Gen Physiol 19:351-371.

Wang JS, Kefalov VJ (2009) An alternative pathway mediates the mouse and human cone visual cycle. Curr Biol 19:1665-1669.

Wang JS, Estevez ME, Cornwall MC, Kefalov VJ (2009) Intra-retinal visual cycle required for rapid and complete cone dark adaptation. Nat Neurosci 12:295-302.

Wenzel A, von Lintig J, Oberhauser V, Tanimoto N, Grimm C, Seeliger MW (2007) RPE65 is essential for the function of cone photoreceptors in NRL-deficient mice. Invest Ophthalmol Vis Sci 48:534-542.

Winkler BS, Kapousta-Bruneau N, Arnold MJ, Green DG (1999) Effects of inhibiting glutamine synthetase and blocking glutamate uptake on b-wave generation in the isolated rat retina. Vis Neurosci 16:345-353.

Wu Q, Blakeley LR, Cornwall MC, Crouch RK, Wiggert BN, Koutalos Y (2007) Interphotoreceptor retinoid-binding protein is the physiologically relevant carrier that removes retinol from rod photoreceptor outer segments. Biochemistry 46:8669-8679.

Yu W, Miller RF (1995) NBQX, an improved non-NMDA antagonist studied in retinal ganglion cells. Brain Res 692:190-194. 